DOI:

\title{
THE SPREAD OF CHINESE LANGUAGE AND CULTURE IN THE CHINESE CULTURAL DISTRICT (UNTIL THE TWENTIETH CENTURY)
}

\author{
Elena Khrisanova \\ Doctor of Pedagogics, Professor \\ I.Yakovlev Chuvash State Pedagogical University \\ (Cheboksary, Russia) \\ e-mail: elenka0304@gmail.com
}

\author{
Yixia Ma \\ Lecturer \\ Guizhou Normal University \\ (Guizhou, China) \\ e-mail: 762495289@qqu.com
}

\begin{abstract}
The article aims to identify on the basis of historiographical analysis of the factors of the spread of the Chinese language and culture and their impact on the development of countries belonging to the Chinese cultural district. The processes of introduction of Chinese in Korea, Japan, Vietnam, Thailand, Indonesia from ancient times to the present time are described. Economic and cultural relations of China and other countries of the district, their domestic and foreign policy in General, including language policy are considered. The positive influence of highly developed Chinese civilization on the development of culture and writing of these countries is shown. The role of ancient Chinese classical books ("LUN Yu", "Pentateuch", "thousand Words", etc.) in teaching the Chinese language to the peoples of the Chinese cultural district is revealed. Progressive changes in the state activity of the countries of the Chinese cultural district are revealed in connection with the introduction of the system of state examinations and the selection of talented officials. The conclusion is made about the positive importance of the Chinese language and culture for the development of neighboring countries; about the factors that had a positive (trade, travel) and negative (war) impact on the spread of the Chinese language and culture in the region.
\end{abstract}

Key words: Chinese cultural district, Chinese culture, language, Chinese writing

\section{РАСПРОСТРАНЕНИЕ КИТАЙСКОГО ЯЗЫКА И КУЛЬТУРЫ В КИТАЙСКОМ КУЛЬТУРНОМ ОКРУГЕ (ДО ХХ ВЕКА)}

\author{
Елена Хрисанова \\ Доктор педагогики, профессор \\ Чувашский государственный педагогический университет им. И. Я. Яковлева \\ (Чебоксары, Россия) \\ e-mail: elenka0304@gmail.com
}

Ися Ма

Преподаватель

Гуйчжоуский педагогический университет

(Гуй Ян, Китайская Народная Республика)

e-mail: 762495289@qq.com

\begin{abstract}
Аннотация. Статья имеет своей целью выявление на основе историографического анализа факторов распространения китайского языка и культуры и их влияния на развитие стран, входящих в китайский культурный округ. Описаны процессы внедрения китайского языка в Корее, Японии, Вьетнаме, Таиланде, Индонезии с древних времен до настоящего времени. Рассмотрены экономические и культурные связи Китая и других стран округа, их внутренняя и внешняя политика в целом, в том числе языковая политика. Показано позитивное влияние высокоразвитой китайской цивилизации на развитие культуры и письменности этих стран. Выявлена роль древнекитайских классических книг («Лунь Юй», «Пятикнижие», «Тысячесловие» и др.) в обучении китайскому языку народов китайского культурного округа. Раскрыты прогрессивные изменения в государственной деятельности стран китайского культурного округа в связи с внедрением системы государственных экзаменов кэцзюй и отбора талантливых чиновников. Сделан вывод о положительном значении китайского языка и культуры для развития соседних стран; о факторах, оказавших положительное (торговля, путешествия) и отрицательное (войны) влияние на распространение китайского языка и культуры в регионе.
\end{abstract}

Ключевые слова: китайский культурный округ, китайский язык, письменность

ВВЕДЕНИЕ. Китайский культурный округ начал формироваться в период династии Хань. В течение длительного времени страны, входящие в этот округ (Китай, Япония, Северная и Южная Корея, другие страны Восточной и Юго-Восточной Азии), испытывали значительное влияние со стороны китайской культуры. Историографические исследования свидетельствуют о том, что объединению стран китайского культурного округа способствовало представление о китайской политике и культуре как единственно верной и самой 
прогрессивной (Lai Anya 2017). Вместе с тем не проводилось системного изучения в области распространения китайского языка и его влияния на развитие культуры, государственности и систем образования соседних с Китаем стран.

ОБЗОР ЛИТЕРАТУРЫ. Изучению и анализу особенностей распространения китайского языка и культуры в странах китайского культурного округа посвящены труды Чжан Цзин (распространение китайского языка на корейском полуострове), Ху Цзэ, Лю Сяофэй (изучение тенденций распространения китайской культуры в Японии), Ху Дэгоин, Чжао Хуэйся (анализ процессов распространения китайского языка во Вьетнаме), Лю Ли, Лу Фан (исторический обзор внедрения китайского языка в Таиланде), Синь Хуэй (развитие китайского образования в Индонезии). Лай Анья выявлены тенденции распространения китайской культуры по всем странам округа. Таким образом, можно рассматривать проблему распространения китайского языка и культуры как достаточно исследованную. Вместе с тем следует отметить, что основная часть трудов опубликована на китайском языке, что делает недоступным знакомство с ними для российских исследователей.

МЕТОДЫ ИССЛЕДОВАНИЯ. Фактические материалы для анализа взяты из опубликованных в Китае научных статей и монографий. Использованы описательный метод, анализ и синтез полученной информации.

РЕЗУЛЬТАТЫ И ДИСКУССИЯ. Китайский язык и культура на Корейском полуострове. Связь между Кореей и Китаем сформировалась еще в древности, что подтверждается документами. В период эпохи Шан начался экономический и культурный обмен между Кореей и Китаем на основе китайского языка. Китайская письменность распространялась в Корее в период Чуньцю (770-476/403 гг. до н.э.) и Сражающихся царств (476/403-221 гг. до н.э.) благодаря торговле. Археологические раскопки в Корее позволили обнаружить металлические монеты, на которых были изображены иероглифы. Таким образом китайское письмо проникало в Корею. На стыке династий Цинь и Хань много китайцев переехало на полуостров Корея, что способствовало распространению китайского языка на корейском полуострове. В 108 году до н.э. Корея была покорена китайской империей Хань, что ускорило распространение китайского языка. В эпоху Вэй, Цзинь, Северных и Южных династий (общий термин для исторического периода 220-589 гг.) на Корейском полуострове сформировалось три государства: Силла, Пэкче, Когурё. Все они активно общались с Китаем. В Силле использовали китайские фамилии, писали государственные хроники на китайском языке. В Когурё с самого начала устройства государства начали использовать китайский язык. На китайском языке создавались прекрасные поэтические произведения.

Долгое время в Корее не было своего письма. Китайский язык использовался элитой страны. Грамматические конструкции и фонетическая система китайского языка совпадали с корейским. Поэтому Седжон-тэван (4-й ван корейского государства Чосон), при котором был изобретен хангыль (фонематическое письмо) создал собственно корейскую национальную азбуку (Zhang Jing 2013).

В середине VI века между государствами Когурё, Пэкче и Силла началась борьба за влияние на Корейском полуострове. Правители Силлы заключили союз с китайской империей Тан: в 660 году под их власть перешло Пэкче, в 668 году - Когурё. В течение 228 лет они тесно взаимодействовали с Китаем. Были открыты государственные школы, из выпускников которых по результатам успехов в изучении китайского языка и культуры выбирали чиновников. Благодаря этому режиму было воспитано много талантливых ученых, специализировавшихся в сфере китайского языка. В 918 году на полуострове установилось правление династии Корё, когда началось официальное обучение китайскому языку.

В период династии Мин отношения между Кореей и Китаем были дружественными. Корея активно распространяла китайский язык и культуру. Но в период династии Цин разразилась японско-китайская война (1894-1895 гг.) с целью установления контроля над Кореей. В результате победы Японии в этой войне в Корее отменили кэцзюйчжи и институты переводов, начали создавать школы иностранных языков. Постепенно китайский язык уступил место японскому, английскому, русскому, немецкому и другим языкам.

Распространение китайского языка в Японии. До династии Тан Япония называлась Ва или Вагоку. Начало распространению китайского языка по легенде положили корейцы Ван Жэнь и А Чжици, которые привезли китайские классические книги «Лунь Юй» и «Тысячесловие» в Японию. В конце правления династии Цзинь в Японии появились государственные историографы, владевшие китайским языком. Это объективно содействовало распространению китайского языка и культуры. В первой половине VI века по просьбе Японии корейцы отправили в эту страну ученых, которые работали как учителя китайского языка, обучали элиту общества. Японцы учились по «Пятикнижию» (конфуцианскому канону), «Тысячесловию» (классическому китайскому мнемоническому тексту, применяемому для заучивания иероглифов) и т.д. В этот период Китай был самым мощным, влиятельным и цивилизованным соседом Японии. Официальных контактов между правительствами Китая и Японии стало больше, поэтому для Японии воспитание ученых и чиновников, знающих китайский язык, являлось приоритетной задачей. В 594 году японский принц Сётоку (574-621) провел реформы, которые были направлены на создание централизованной исполнительной вертикали власти и распространение буддизма. В 604 году на китайском языке были написаны «Законоположениями в семнадцати статьях», был введен китайский календарь. Япония также посылала в Китай монахов для изучения буддийских канонов, каллиграфии, а также китайской медицины (например, монах Цзянь Чжэнь). В течение 300 лет Япония училась у Китая, вследствие чего общество и культура Японии быстро развивались.

До 1861 года между Китаем и Японией не было дипломатических отношений. В распространении китайского языка и культуры в Японии важную роль сыграла династия Цин (1644-1911 гг.). В период ее правления происходило бурное развитие торговли между Китаем и Японией. Поэтому к переводчикам предъявлялись очень строгие требования. Для изучения китайского языка использовались фонетические 
учебники: «Да сюэ» («Великое учение», 2-я книга конфуцианского «Четверокнижия»), «Лунь Юй» (главная книга конфуцианства); конфуцианское «Четверокнижие», «Мэнцзы», «Ши цзин» (записи древних песен, гимнов и стихов XI-VI вв. до н. э.). После фонетики изучались устойчивые выражения. Далее язык можно было изучать на более продвинутом уровне. Будущим переводчикам необходимо было читать китайские классические романы, например «Речные заводи» Ши Найаня (китайский роман XIV века), «Западный флигель» Ван Шифу, «Троецарствие» (роман, повествующий о событиях эпохи Троецарствия). После Опиумных войн, развязанных Великобританией и Францией, Китай постепенно превращался в полуколониальную и полуфеодальную страну. Япония после Реставрации Мэйдзи (реставрации «просвещенного правления», которая известна также как Обновление Мэйдзи и Революция Мэйдзи) стала сильной страной. В результате стали распространяться японский язык и японская культура (Hu Ze and Liu Xiaofei 2018).

Распространение китайского языка и культуры во Вьетнаме. В древности Вьетнам назывался Цзяо Чжи. В эпоху династии Цинь правительство посылало туда преступников, которые жили среди местных жителей. С этого времени началось распространение китайского языка и культуры. Во времена правления Эрши Хуан-ди (229-207 до н.э.) китайский князь Чжао Та стал царем в Южном Вьетнаме. При императоре Лю Бана (256 или 247-195 гг. до н.э.) ему официально был присвоен ему титул царя Южного Вьетнама. В этот период в стране активно насаждался китайский язык.

Во времена правления У-ди (156-87 гг. до н. э.) Вьетнам был разделен на девять округов, куда посылали китайских чиновников. Эти чиновники под влиянием идей конфуцианства принимали полезные для народа, гуманные управленческие решения, что способствовало социальной стабильности и распространению китайского языка и культуры. В эти времена чиновники даже избирались по тем же критериям, что и в Китае.

В период династии Сун в 1232 году во Вьетнаме была введена китайская система государственных экзаменов для получения ученой степени и права вступления в должность. В 1246 году в хрониках Вьетнама первый раз появилось понятие «цзиньши» (высшая ученая степень в системе государственных экзаменов кэцзюй), в 1247 году - другие китайские термины: первый из сильнейших - победитель на столичных экзаменах, первый кандидат на высокую должность, второй из сильнейших (второй в списке выдержавших столичные экзамены), «искатель цветов» (занявший третье место на государственных экзаменах).

Во Вьетнаме китайский язык называли «языком конфуцианства». Вьетнамцы создали «тьы-ном» систему письма на основе китайской иероглифики, которая использовалась для записи вьетнамского языка.

В период династии Юань правительство Китая строило захватнические планы по отношению к Вьетнаму, однако впоследствии политический курс изменился в сторону добрососедства и культурного обмена. Китайский язык активно распространялся среди населения. У вьетнамцев стали формироваться обычаи, похожие на китайские. В начале правления династии Мин Вьетнам был своего рода вассалом Китая. Но в 1406 году между ними разразилась война. В 1427 году правительство Китая вывело армию из Вьетнама. Во Вьетнаме стала господствовать династия Ли, первый император которой, воспользовавшись китайской военной стратегией, добился автономии. В 1862 году правительства Вьетнама и Франции подписали Сайгонский договор. Французы ограничили распространение китайского языка и культуры. В 1919 году во Вьетнаме был проведен последний раз кэцзюй. В 1945 году китайский язык был официально аннулирован (Hu Deguoyin, 2018).

Распространение китайского языка и культуры в Таиланде. В Таиланде существовало два типа школ китайского языка: частные и государственные. В XIV веке в городах, где кучно жили этнические китайцы, было развито китайское образование. Преподавали «Четыре книги и пять канонов» (четыре книги: «Лунь Юй», «Мэнцзы», «Да сюэ», «Чжун юн»; пять канонов: «И цзин», «Шу цзин», «Ши цзин», «Ли цзи», «Чуньцю»). Но таких школ было мало. В начале XX века Сунь Чжуншань (китайский революционер-демократ, основатель партии Гоминьдан) организовал Объединенный союз, через который активно популяризировал китайский язык и литературу. В 1919 году этнические китайцы создали школу китайского языка Хуа И. Это стало началом открытия сугубо китайского образования. Постепенно появились школы китайского диалектного языка. До 1915 года функционировали 12 школ китайского языка. В 1922 году правительство Таиланда изменило языковую политику. Согласно новым правилам, дети в возрасте 7-12 лет обязательно получали таиландское образование. Это касалось также детей этнических китайцев. Данные правила с трудом принимались сообществом китайцев в Таиланде, они активно протестовали против нововведений, по причине чего данная языковая политика в течение 10 лет продвигалась с большим трудом (Liu Li, 2017).

После создания Китайской Народной Республики в Таиланде царили антикоммунистические и антикитайские настроения, поэтому к 1987 году насчитывалось только 125 школ китайского языка. В феврале 1991 года в Таиланде была введена новая политика, согласно которой китайский язык имеет одинаковый статус с английским, японским, французским и немецким языками. В последние годы при поддержке принцессы Маха Чакри Сириндхорн правительство Таиланда активно распространяет китайский язык и культуру (Zhao Нuаiхia and Lu Fang, 2019).

Распространение китайского языка и культуры в Индонезии. В исторических книгах есть упоминания, согласно которым самая первая школа китайского языка в Индонезии была открыта в 1690 году. Учебниками в ней были «Троесловие», «Байцзясин» (рифмованный список китайских фамилий для заучивания иероглифов наизусть), «Тысячесловие» (классический китайский мнемонический текст, применяемый для заучивания иероглифов) и «Четыре книги и пять канонов» (четыре книги: «Лунь Юй», «Мэнцзы», «Да сюэ», «Чжун юн»; пять канонов: «И цзин», «Шу цзин», «Ши цзин», «Ли цзи», «Чуньцю»).

В конце XIX - начале XX века много роялистов и республиканцев из Китая поехали в Индонезию распространять китайский язык и культуру. В 1906 году правительство Цин создало школу Цзи-нань (районы 
расселения китайских эмигрантов в Южных морях), куда приехали обучаться множество учащихся из Индонезии. В 1908 году голландские колонисты открыли школы, в которых не изучался китайский язык. Правительство Индонезии постановило, что школы китайского языка могут быть только частными, вследствие чего они не имели прав на получение государственной помощи. Правительство также не признавало их образовательный ценз. В 1942-1945 годах в Индонезии китайский язык могли изучать только в начальных школах. В 1950 году во время объединения Индонезии функционировало 816 школ китайского языка, но в этих школах процветал китайский национализм, что привело к активным антикитайским настроениям. В 1967 году Индонезия прервала дипломатические отношения с Китаем, которые были восстановлены лишь в 1990 году. С этого времени китайский язык стал вновь преподаваться в школах (Xin Hui, 2014).

ЗАКЛЮчЕНИЕ. Анализ истории свидетельствует о высокой оценке роли китайского языка и культуры в развитии государств китайского культурного округа. В аспекте цивилизованности Северная Корея, Япония, Вьетнам и другие страны долгое время отставали от Китая, поэтому освоение языка и культуры Китая стало неизбежным требованием национального развития и единственным выбором для этих стран. Овладение китайским иероглифическим письмом являлось способом повышения чиновников в должности. Бизнесмены также могли извлечь выгоду из экономических и торговых обменов с Китаем. В настоящее время китайский язык и культура активно интегрируются в мировое культурное сообщество, а опыт массового продвижения китайского языка в мире все еще находится в стадии накопления.

\section{LIST OF REFERENCES}

Hu Deguoyin. (2018) Analysis of the spread of Chinese language and culture in Vietnam. International Communication, p.p. 76-84 $\mathrm{Hu} \mathrm{Ze}$, Lin Xiaofei (2018) Research on the interaction between Chinese and Japanese languages. Changchun University Bulletin, p.p. $76-79$

Lai Anya (2017) Study of the spread of the Chinese language in the world within the framework of "one belt - one road». Fuzhou Pedagogical University Press, 2017.

Liu Li (2017) Research on the integration of Chinese language teaching and the spread of Chinese culture in Thailand. Education and Teaching Methods, p.p. $75-80$

Xin Hui (2014) Overview of teaching Chinese in Indonesia. Jiaozuo Pedagogical College Bulletin, p.p. 47-49

Zhang Jing (2013) Study of the spread of Chinese language and culture in South Korea. Chinese National University Press, 2013.

Zhao Huaixia, Lu Fang (2019) Changes in Chinese education policy and development of Chinese education in Thailand. Hainan Science-Technology University Bulletin, p.p. 67-73

\section{For citation:}

Khrisanova Elena \& Ma Yixia (2019) THE SPREAD OF CHINESE LANGUAGE AND CULTURE IN THE CHINESE CULTURAL DISTRICT (UNTIL THE TWENTIETH CENTURY) // International Scientific-Pedagogical Organization of Philologists “WEST-EAST” (ISPOP). Scientific Journal WEST-EAST. Vol 2/1 N1 (October, 2019). pp.44-47. doi:

Для цитирования:

Хрисанова Елена, Ма Ися (2019) РАСПРОСТРАНЕНИЕ КИТАЙСКОГО ЯЗЫКА И КУЛЬТУРЫ В КИТАЙСКОМ КУЛЬТУРНОМ ОКРУГЕ (ДО ХХ ВЕКА) // Internationa 1Scientific-Pedagogical Organization of Philologists “ WEST-EAST ” (ISPOP) . Scientific Journal WEST-EAST. Vol 1/1 N1 (October, 2019). C. 44-47. doi:

Information about the authors: Elena Khrisanova - PhD, prof., Yakovlev Chuvash State Pedagogical University (Cheboksary, Russia)

e-mail: elenka0304@gmail.com

Ma Yixia - lecturer, Guizhou Normal University (Guizhou, China)

e-mail: $\underline{762495289 @ \text { qq.com }}$

Сведения об авторах: Елена Хрисанова- Доктор педагогики, профессор Чувашский государственный педагогический университет им. И. Я. Яковлева (Чебоксары, Россия)

e-mail: elenka0304@gmail.com

Ися Ма - Преподаватель, Гуйчжоуский педагогический университет (Гуй Ян, Китайская Народная Республика) e-mail: 762495289@qq.com 